
MonRAD-KROHN, G. H. $\quad$ - . $\quad$. 1923. In The neurological aspect of leprosy ("Spédalskhed "), Christiana, 70, 11- 12.

ReES, R. J. W., WATERS, M. F. R., 1967. Nature, Lond., 215, 599.

Weddell, A. G. M., AND Palmer,

ELISABETH

SUDAKEWITSCH, J.

1888. Beitr. path. Anat., 2, 129.

UHLENHUTH $\quad . \quad$. . . . . . 1900. Dt. med. Wschr., 26, 127.

\title{
ELECTRON MICROSCOPY OF GIARDIA LAMBLIA \\ IN HUMAN JEJUNAL BIOPSIES
}

\author{
S. E. H. Brooks, Johanna Audretsch, C. G. Miller and B. Sparke \\ Departments of Pathology and Paediatrics, University of the West Indies, Mona, \\ Jamaica
}

Plates XV-XIX

DESCRIPTIONS of the fine structure of Giardia lamblia and its relations to the intestinal mucosa are few. Rossi-Espagnet and Piccardo (1957) examined whole mounts of the parasite with the electron microscope without extending descriptions beyond the light-microscope appearances. Cheissen (1964) reported on the ultrastructure of Lamblia duodenalis in rabbits. Takano and Yardley (1965) described Giardia lamblia from human intestinal biopsies and more recently Morecki and Parker (1967) described the ultrastructure of the human Giardia, presenting a case in which the parasite had apparently penetrated the mucosal cells. In both these papers fixation was in osmium tetroxide. Friend (1966) reported in detail the ultrastructure of Giardia muris, for which he used a glutaraldehyde-acrolein fixative with osmium tetroxide post-fixation.

In this paper, we present descriptions of the electron-microscopic appearances of Giardia lamblia, found in jejunal biopsies from three patients and fixed in glutaraldehyde.

\section{METHODS}

Peroral jejunal biopsy was performed with a Watson intestinal biopsy capsule. The biopsy was divided into two parts for light and electron microscopy. The first part was fixed in 4 per cent. formaldehyde and after examination under a dissecting microscope it was embedded in paraffin; sections were stained with haematoxylin and eosin. The other part of the biopsy was fixed for electron microscopy by immediate immersion in 2.5 per cent. glutaraldehyde in $0.1 \mathrm{M}$ phosphate buffer $\left(p \mathrm{H} \mathrm{7.4)}\right.$ at $4^{\circ} \mathrm{C} ; 1-\mathrm{mm}$ pieces were trimmed and fixation was carried out for $2 \mathrm{hr}$. After overnight washing in buffer, the tissues were post-fixed in 1 per cent. phosphate-buffered osmium tetroxide, dehydrated through graded alcohols, passed through propylene oxide, embedded in Maraglas and polymerised at $60^{\circ} \mathrm{C}$ for $18 \mathrm{hr}$. $1-\mu \mathrm{m}$ sections were stained with toluidine blue and examined by light microscopy. Thin sections were cut on an LKB Ultrotome with glass knives and stained with uranyl acetate followed by lead citrate, or lead citrate alone (Reynolds, 1963). Electron microscopy was carried out with a Philips $100 \mathrm{C}$ at $60 \mathrm{kV}$. 


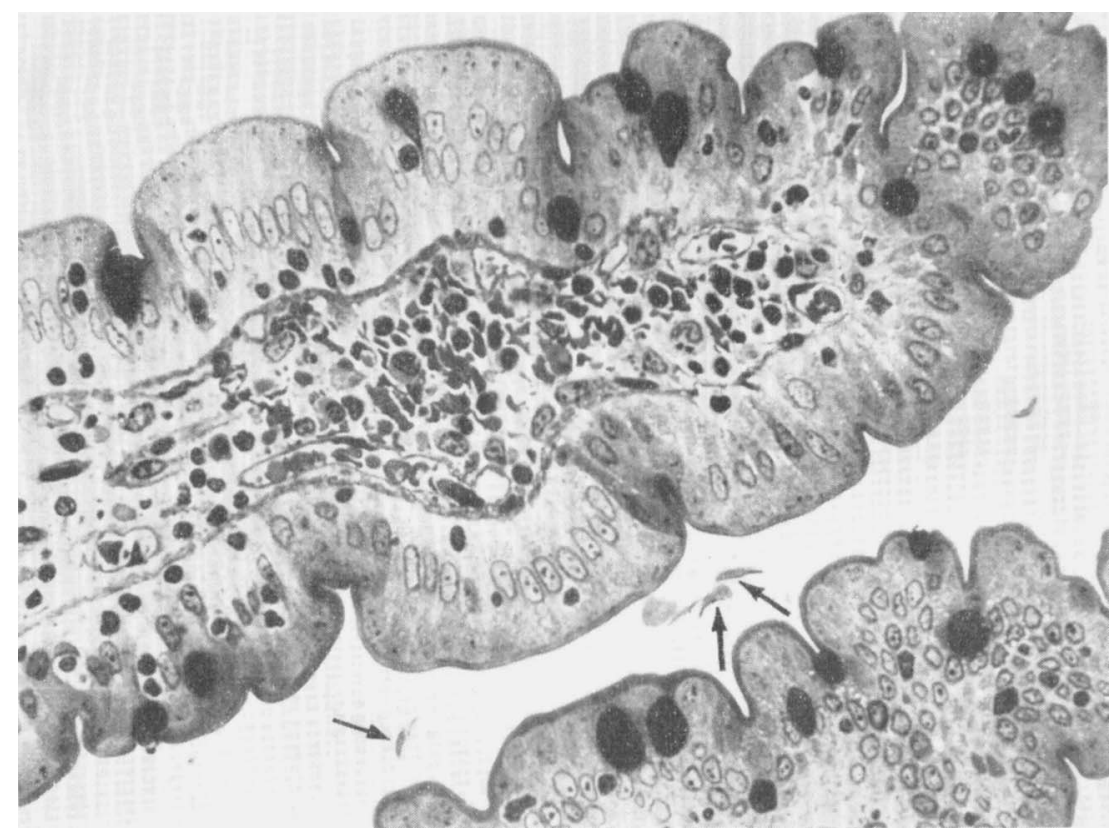

FIG. 1.-Portions of two villi from jejunum of case 2. The epithelial cells show no abnormality. In the lumen there are several Giardia lamblia trophozoites (arrows). Glutaraldehyde fixation. $1-\mu \mathrm{m}$ section stained with toluidine blue. $\times 550$.

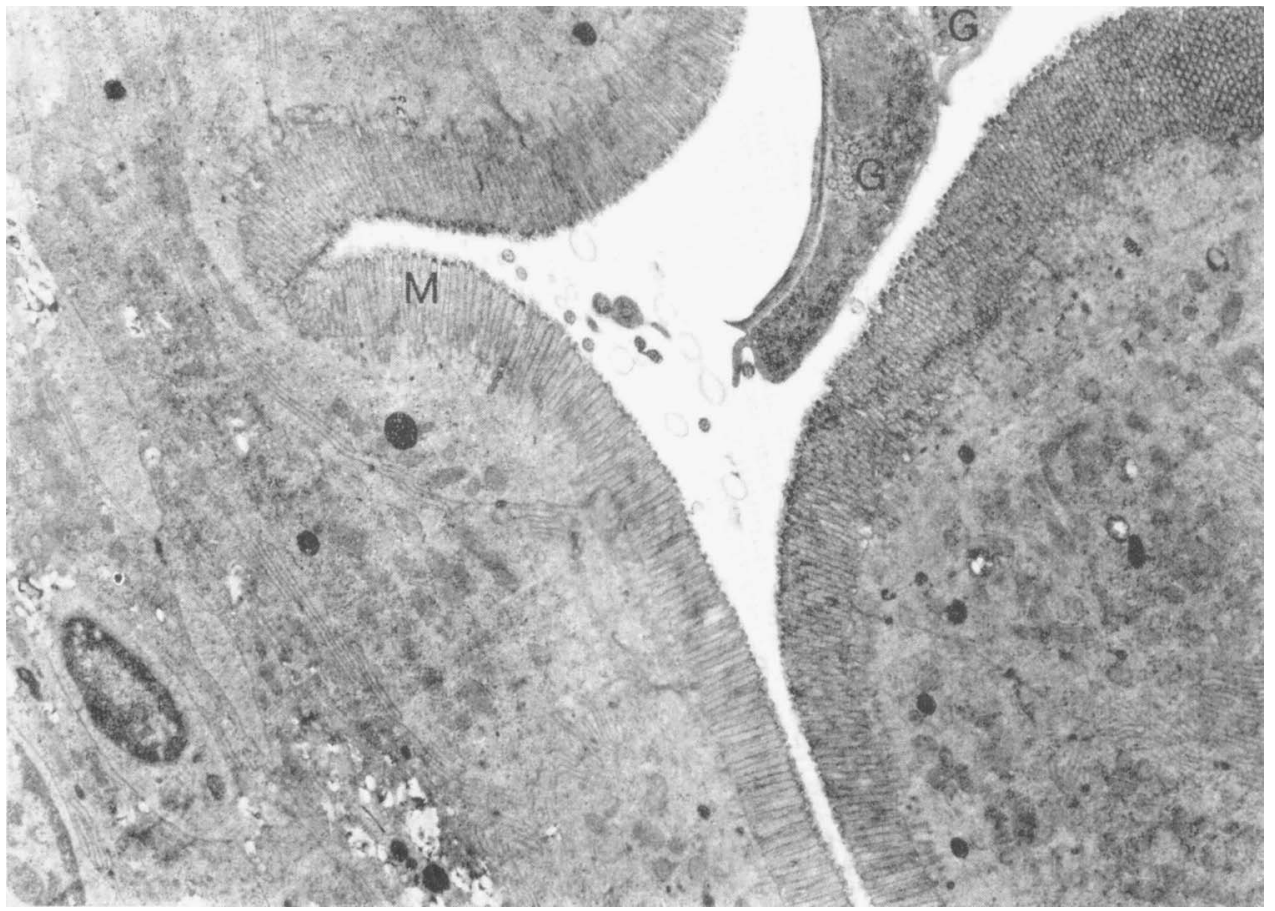

FIG. 2.-Electron micrograph of jejunal epithelium. Uniform microvilli (M); portions of two parasites lying in the lumen $(\mathrm{G})$. Lead citrate. $\times 6000$. 


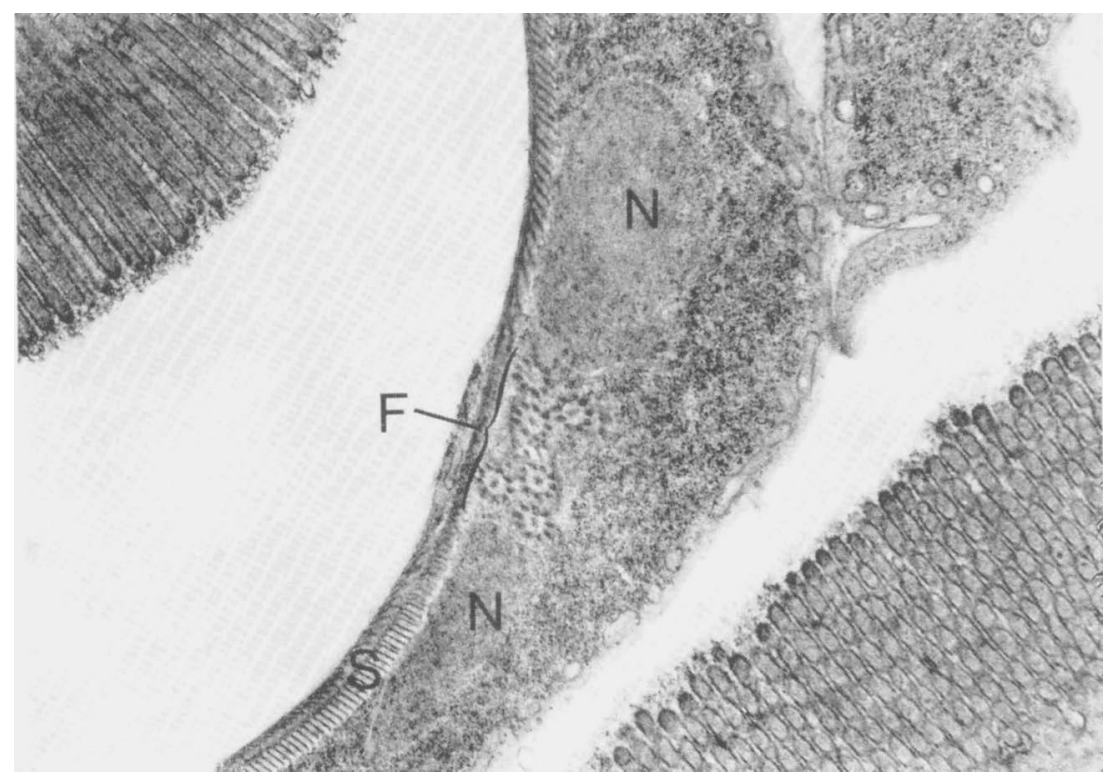

FIG. 3.--Higher magnification of trophozoite in fig. 2. The larger protozoan is cut transversely. Cross-sections of six flagella are evident $(\mathbf{F})$, as are the paired nuclei $(\mathrm{N})$ and prominent striated disc (S). Lead citrate. $\times 16,500$.

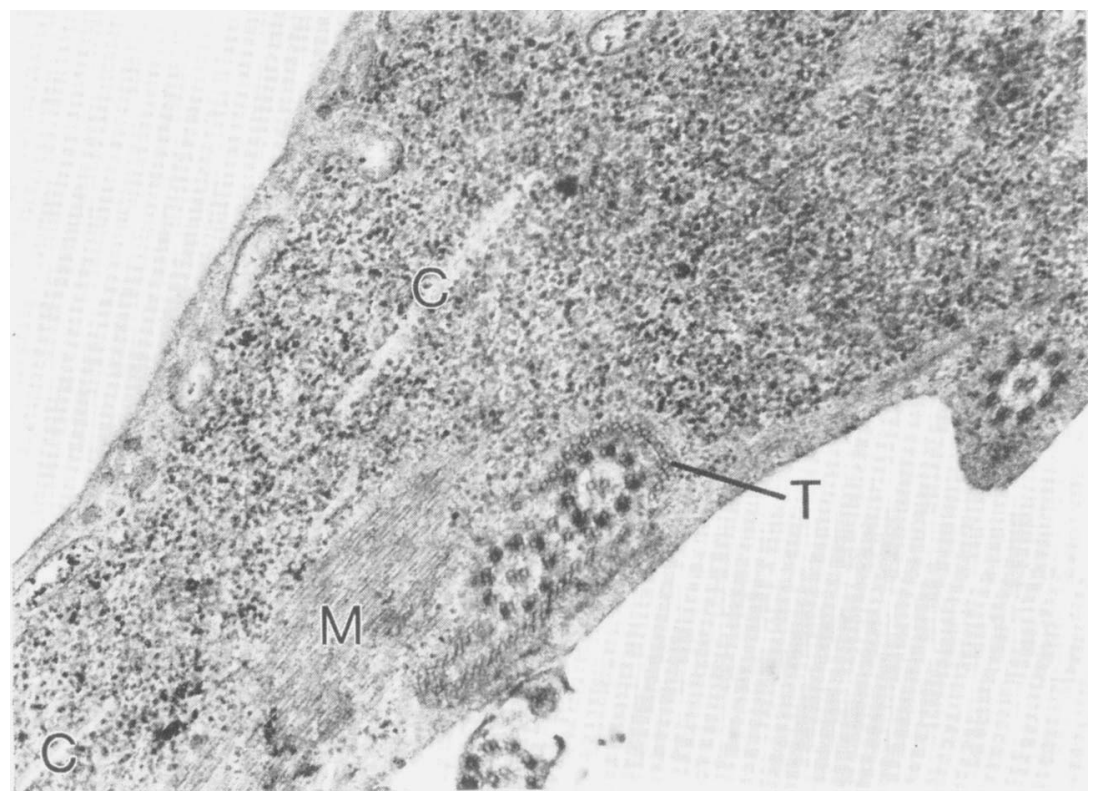

FIG. 4.-Detail of intracytoplasmic flagella. Curved row of tubular profiles (T), the microtubules of the median body (M) and cytoplasm with numerous granules and clefts (C). Lead citrate. $\times 33,000$. 


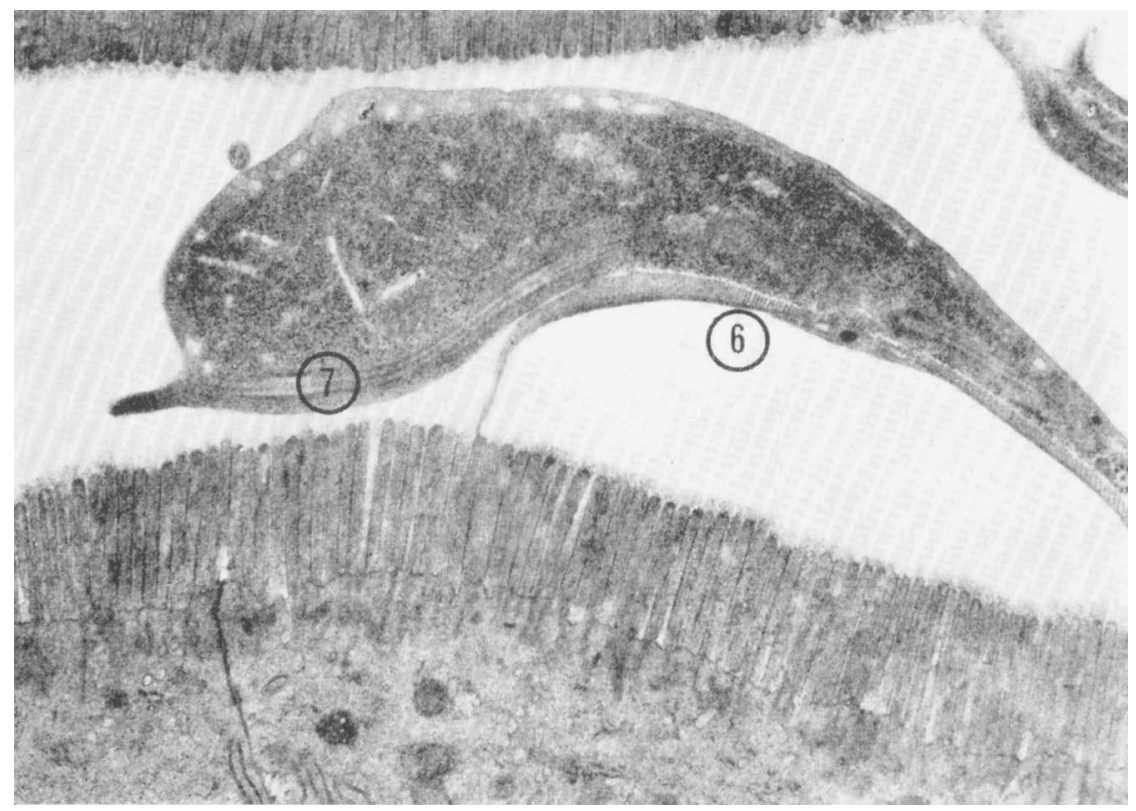

FIG. 5.-Longitudinal section of Giardia lying in lumen. Areas shown at higher magnification in figs. 6 and 7 are indicated by numbers in circles. The microvilli of the intestine are uniform and regular. Lead citrate. $\times 13,900$.

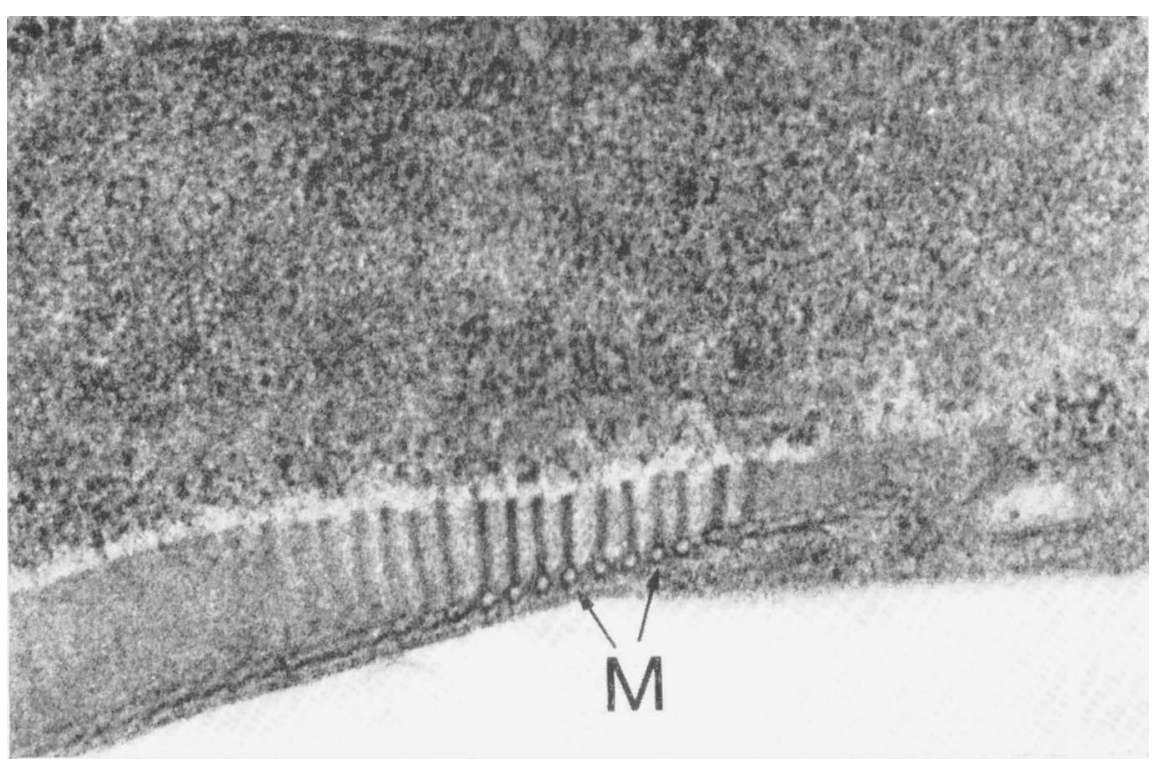

FIG. 6.-Higher magnification of area in fig. 5. Striated disc consisting of microtubules (M) with parallel fibres. Lead citrate. $\times 108,000$. 


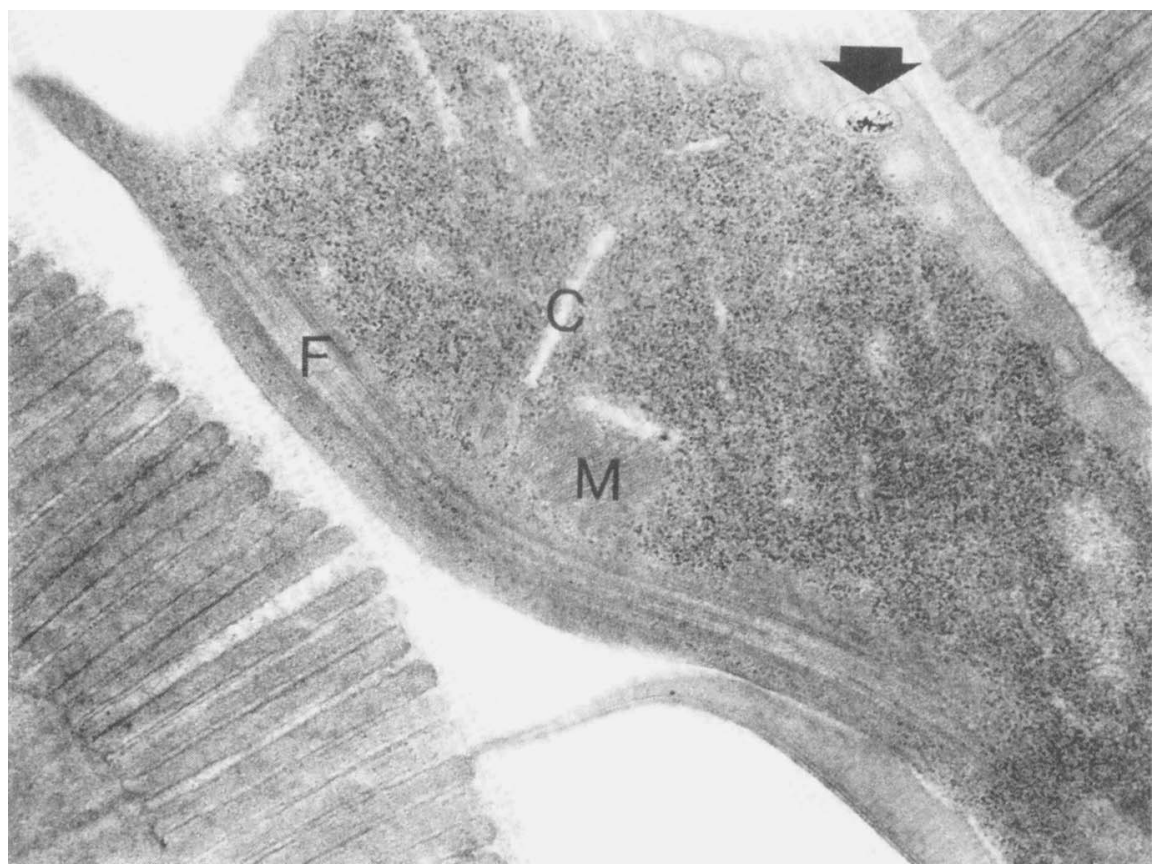

Fig. 7.-Another area from fig. 5 at higher magnification. Prominent intracytoplasmic anterior flagellum (F) and the microtubules of the median body $(\mathrm{M})$. The cytoplasm shows numerous granules and clefts $(\mathrm{C})$. On the upper surface is an agranular zone in which vacuoles are seen in a row. Some dense inclusions in one vacuole are indicated by an arrow. Lead citrate. $\times 29,600$.

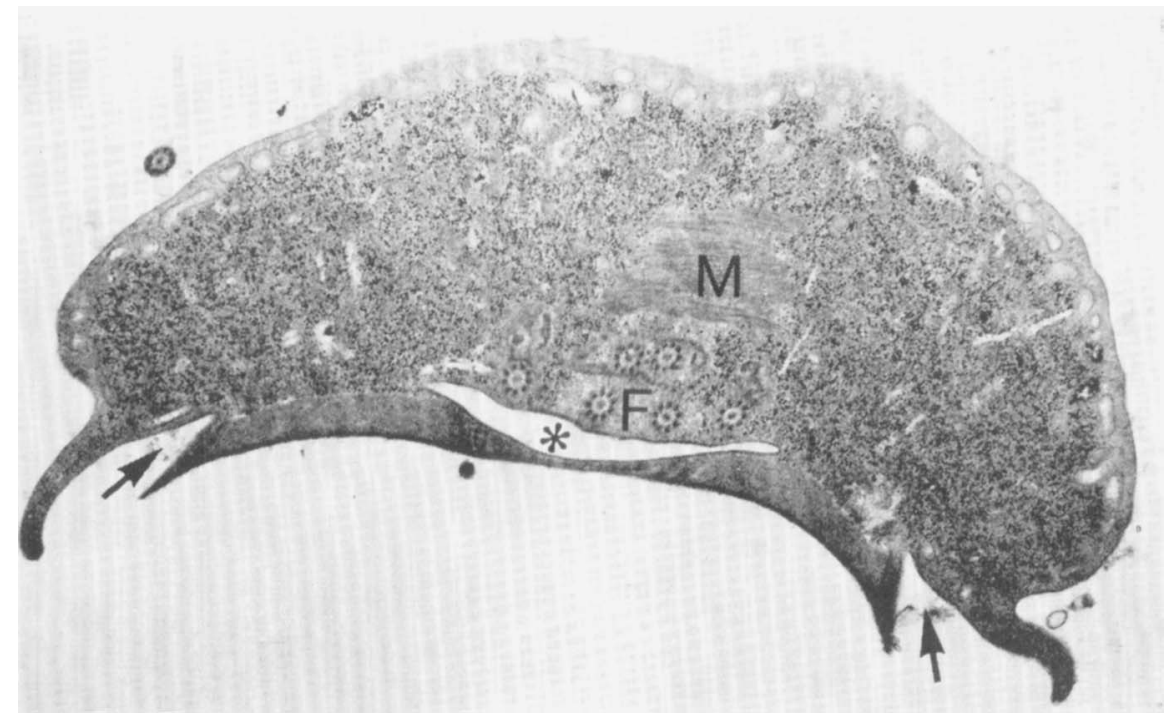

FIG. 8.--Transverse section of Giardia lamblia. Median body (M), six intracytoplasmic flagella (F) and a membrane-lined ventral cleft $(*)$. The marginal grooves are shown by arrows. Lead citrate. $\times 16,500$. 


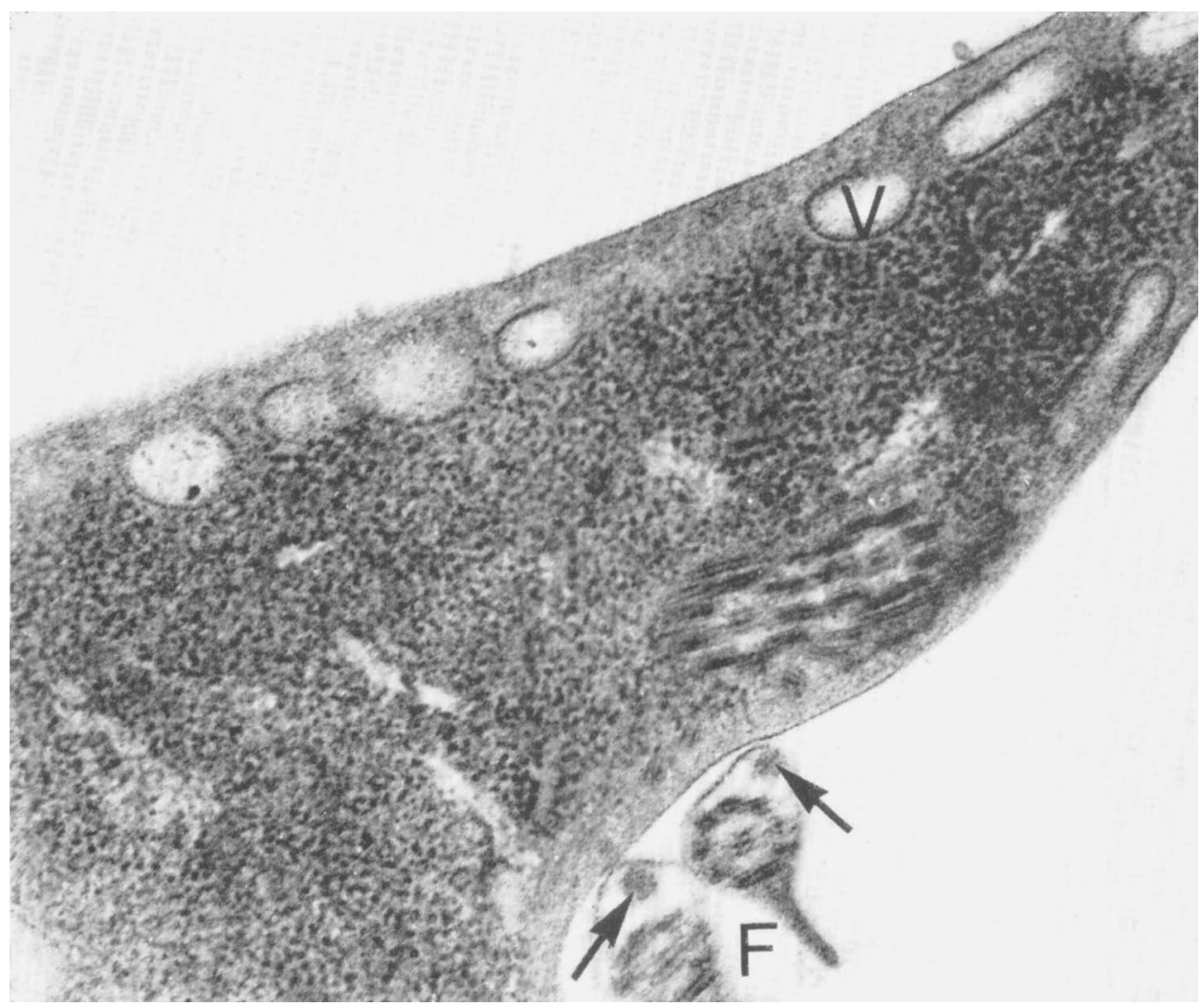

FiG. 9.-Cross-section of two flagella (F): typical fine structure with hollow tubules. Each extracellular flagellum is surrounded by a rim of cytoplasm which also contains a dense body (arrows). Peripheral vacuoles prominent (V). Lead citrate. $\times 69,000$. 


\section{CASE MATERIAL}

Jejunal biopsies showing Giardia lamblia were obtained from three patients. In only one case was the protozoan considered to be causing clinical disease.

Case 1. This was a 6-yr-old girl who was admitted to another hospital on 27 Mar. 1968. On examination she was small for her age; there was generalised oedema, angular stomatitis, anaemia and typical skin and hair changes of kwashiorkor. She was given a normal ward diet and lost her oedema, but failed to gain weight over a 3-mth period, although her haemoglobin increased from 8.3 to $10.3 \mathrm{~g}$ per $100 \mathrm{ml}$ and her serum proteins from 4.7 to $6.5 \mathrm{~g}$ per $100 \mathrm{ml}$ (albumin 1.7 to $3.3 \mathrm{~g}$ per $100 \mathrm{ml}$ ). She was transferred to the University Hospital on 27 June 1968.

On examination, she weighed $13.3 \mathrm{~kg}$ and in addition to being malnourished and small for her age, she was noted to have clubbing of her fingers and toes. Examination of her cardiovascular and respiratory systems revealed no abnormality.

Investigations showed normal liver and kidney function and no evidence of malabsorption: xylose absorption and fat excretion tests were normal. Giardia lamblia cysts were found in one of five stool specimens examined. Immediately after admission her appetite was poor and on a normal ward diet she had two or three loose stools daily. Diarrhoea subsided spontaneously and her appetite improved after a week, although no significant weight gain occurred for the first $3 \frac{1}{2} \mathrm{wk}$. She then gained $1.5 \mathrm{~kg}$ in a week. A course of Mepacrine, $25 \mathrm{mg}$ three times daily for 5 days, was then administered; rapid weight gain continued until her discharge on 16 Aug. 1968 , when she weighed $16.8 \mathrm{~kg}$. She has remained well since discharge and weighed $17 \mathrm{~kg}$ when last seen on $2 \mathrm{Jan} .1969$.

Case 2. This was a 5-yr-old boy who had had blisters on the forearms and legs for a year and was diagnosed at the University Hospital as a case of juvenile dermatitis herpetiformis. A jejunal biopsy was taken as part of a study on intestinal function in this disorder and Giardia was found incidentally.

Case 3. A 6-mth-old boy was admitted on 11 Sept. 1968 with a history of recurrent gastro-enteritis and failure to thrive. He was grossly malnourished and dehydrated, with signs of right otitis media. Treatment with intravenous fluids and penicillin was given initially, followed by graduated oral feeds. As pathogenic Escherichia coli were cultured from his stool he was also given a 6-day course of neomycin. The diarrhoea subsided within a few days, but he failed to gain weight over a 9-wk period, in spite of a good appetite and an adequate calorie intake. A chest X-radiograph and barium meal showed no abnormality. Stool fat was within normal limits (7.4 g excreted over a 3-day period), but xylose absorption and excretion were abnormally low: serum xylose $17 \mathrm{mg}$ per $100 \mathrm{ml}$ at $1 \mathrm{hr}$, and $19 \mathrm{mg}$ per $100 \mathrm{ml}$ at $2 \mathrm{hr}$ (normal: $32-67 \mathrm{mg}$ per $100 \mathrm{ml}$ ). Urinary excretion of xylose 9.9 per cent. of oral dose in $5 \mathrm{hr}$ (normal: 13-31 per cent.).

His urine was normal and the blood urea was $28 \mathrm{mg}$ per $100 \mathrm{ml}$. No ova or cysts were seen in the two stool specimens examined. He was discharged on 14 Nov. 1968 weighing $5.0 \mathrm{~kg}$. After this he gained weight slowly and when last seen on 21 Apr. 1969 he weighed $6.6 \mathrm{~kg}$ at $13 \mathrm{mth}$.

\section{RESULTS}

Under the dissecting microscope, the biopsy from case 1 showed a pattern of ridges and convolutions; histologically the villous profiles appeared shortened. Case 2 had a pattern of short ridges and leaves. Giardia was seen as an incidental histological finding and is illustrated in fig. 1. Case 3 also showed minimal gross and microscopic alterations, and Giardia was detected in the course of electron microscopy. In none of our cases was Giardia seen in the mucosa or submucosa.

\section{Electron microscopy}

In the three cases studied, there is no evidence of invasion of the parasite into the mucosa or deeper tissues. The microvilli appear normal and are covered with the usual mucopolysaccharide coat (figs. 2 and 3). The interdigitating plasma membranes of the mucosal cells 
appear normal. In case 1 lysosomes are very numerous in the cells, and in case 3 there are collections of lipid in the epithelial cells. Electron micrographs of the parasite (figs. 2, 3, 4) show a binucleate structure. No nucleoli are evident. There is a prominent "adhesive disc " consisting of a layer of microtubules linked to the endoplasm by fibrous bands (figs. 5 and 6). Friend suggested that this structure should be referred to as the striated disc as it appears to have a supporting rather than an attachment function. Giardia has eight flagella with typical ultrastructure. Two are located laterally. Intracytoplasmic cross-sections of six in a central group are well shown in fig. 4 , and longitudinal sections in fig. 7. Portions of extracytoplasmic flagella are seen in figs. 4 and 9. In fig. 4 the median body is seen, consisting of parallel microtubules and without a limiting membrane. Just beneath the dorsal surface there are a series of vacuoles having no connexions with the outer limiting membrane; few contain dense particles (fig. 7). The cytoplasm is filled with numerous granules, which other writers have interpreted as ribosomes and possibly carbohydrate storage particles. Fusiform clefts without membranes are present in the cytoplasm, but there is no recognisable endoplasmic reticulum, Golgi complex, mitochondria or lysosomes. There are a pair of marginal grooves (fig. 8) and a ventral groove. The illustrations in the paper by Friend show in transverse section a space between separate lateral ridges of the adhesive disc. In fig. 8 it can be seen that the lateral ridges fuse at one level to form a channel.

\section{Discussion}

In three patients with very different histories Giardia lamblia was found, raising the much debated point of whether their presence has any significance (Brandborg et al., 1967). One patient (case 1) was suspected of having clinical symptoms due to giardial infestation, but this was not proven, as her clinical condition began to improve prior to the administration of therapy for giardiasis.

Another patient (case 3) had a history of recurrent diarrhoea and failure to thrive, with demonstrable evidence of malabsorption. The latter finding, however, may have been secondary to the oral administration of neomycin, as this drug has been shown to be capable of producing a coeliac disease-like syndrome (Jacobson, Prior and Faloon, 1960). In the third case the parasite was found incidentally. A careful search was made in all three patients for evidence of entry of the parasite into the host cells, but this could not be demonstrated. Morecki and Parker (1967) and Brandborg et al. (1967) have shown evidence of mucosal invasion in a number of human cases.

The ultrastructural features are interesting in that the peripheral vacuoles, median body and cytoplasmic clefts are unique among protozoa whose fine structure has been described to date (Friend, 1966). The absence of organelles such as mitochondria, endoplasmic reticulum and Golgi complex may be an anatomical reflection of the protozoon's adaptation to a parasitic life.

\section{SUMMARY}

A description is given of the ultrastructure of Giardia lamblia found in three jejunal biopsies from children. The unique median body, vacuoles and cytoplasmic clefts of this protozoon are illustrated. No evidence of penetration of the trophozoite into the jejunal mucosa or deeper tissues is demonstrable.

This work was supported in part by a Grant from the Wellcome Trust to one of the authors (S. E. H. B.).

\section{REFERENCES}

BrandBorG, L. L., TANKersLey, C. B., 1967. Gastroenterology, 52, 143.

GotTlieb, S., Barancik, M., AND

SARTOR, V. E.

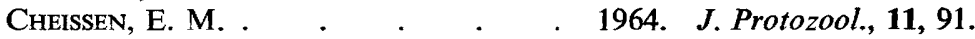

FrIEND, D. S. $\quad . \quad$. $\quad$. $\quad$. $\quad$. 1966. J. Cell Biol., 29, 317. 
JACOBson, E. D., Prior, J. T., AND 1960. J. Lab. Clin. Med., 56, 245.

FALOON, W. W.

Morecki, RaChel, AND PARKer, J. G. . 1967. Gastroenterology, 52, 151.

ReYNolds, E. S. . $\quad$. $\quad$. $\quad$. 1963. J. Cell Biol., 17, 208.

Rossi-Espagnet, A., AND Piccardo, 1957. Riv. Parassit., 18, 213.

M. G.

TAKano, J., ANd Yardley, J. H. 1965. Bull. Johns Hopkins Hosp., 116, 413.

Vol. 2, No. 4, November 1969, was issued on 6.2.70. 